\title{
DISPOSABLE NON-MECHANICAL ELASTOMERIC BALLOON PUMP FOR CONTINUOUS EPIDURAL INFUSION: AN EFFECTIVE AND RELIABLE MEANS FOR POSTOPERATIVE ANALGESIA
}

\author{
Dilip Kumar Saloi ${ }^{1}$, Mrinal Kanti Taye $^{2}$, Subhankar Paul ${ }^{3}$
}

${ }^{1}$ Assistant Professor, Department of Anaesthesiology \& Critical Care, Gauhati Medical College \& Hospital, Guwahati, Assam. ${ }^{2}$ Assistant Professor, Department of Anaesthesiology \& Critical Care, Gauhati Medical College \& Hospital, Guwahati, Assam. ${ }_{3}^{3}$ Post Graduate Student, Department of Emergency Medicine, Gauhati Medical College \& Hospital, Guwahati, Assam.

\section{ABSTRACT}

Postoperative pain an unpleasant sensory and emotional experience is one of the most challenging and gratifying domains to treat. Aim is here to assess effectiveness of postoperative pain relief, side effects and complications while using non-mechanical disposable elastomeric pump as continuous epidural infusion.

\section{PATIENTS AND METHODS}

The present study has been carried out on thirty patients in postoperative wards. At the end of operation the Elastomeric pump containing $125 \mathrm{ml}$ of bupivacaine $(0.125 \%)$ was connected with the epidural catheter Pain was assessed by VAS scoring system ranging from 0 to 10. Haemodynamic parameters, quality of analgesia, degree of motor block, and adverse effect encountered were recorded at two hours interval for 24 hours at the end of two hours of subarachnoid block when operation is over.

\section{RESULTS AND OBSERVATIONS}

None of our patients had shown any clinically significant changes in their cardiorespiratory indices in the postoperative period. All the patients at $0 \mathrm{hr}$. were having VAS score of 0 and till 22 hours enjoyed good pain relief, i.e. VAS of 3-4. Infusion is not always steady as set by the manufacturer. There is no motor blockade after 16 hours (Bromage-0). Insignificant number of patients experienced nausea or vomiting and backache.

\section{CONCLUSIONS}

Elastomeric balloon pumps is a reliable device to deliver LA agents steadily and safely with $0.125 \%$ bupivacaine as continuous epidural.

\section{KEYWORDS}

Post-operative Pain, Elastomeric Pump, Epidural Infusion, Reliable Device.

HOW TO CITE THIS ARTICLE: Saloi DK, Taye MK, Paul S. Disposable non-mechanical elastomeric balloon pump for continuous epidural infusion: an effective and reliable means for postoperative analgesia. J Evolution Med Dent Sci 2016;5(2):154-160, DOI: $10.14260 /$ jemds/2016/36

\section{INTRODUCTION}

Pain an unpleasant sensory and emotional experience associated with actual or potential tissue damage or described in terms of such damage. The management of postoperative pain is one of the most challenging and gratifying domains of anaesthesia. It is conceivable that the improved moral and mobility resulting from good pain relief after surgery contribute to more rapid and complete recovery.[1] Epidural analgesia is one of the most effective techniques available for the management of acute pain as well as it reduces the incidence of thrombosis of vascular grafts, myocardial ischaemia, dysrhythmias and incidence of infection. ${ }^{[2,3]}$ Aim is here to assess effectiveness of postoperative pain relief, side effects and complications while using non-mechanical disposable elastomeric pump as continuous epidural infusion with bupivacaine.

\section{PATIENTS AND METHODS}

The present study has been carried out on thirty patients in orthopaedic, urology, surgery and gynaecology operation

Financial or Other, Competing Interest: None.

Submission 25-12-2015, Peer Review 26-12-2015,

Acceptance 01-01-2016, Published 07-01-2016.

Corresponding Author:

Dr. Mrinal Kanti Taye,

Gauhati Medical College \& Hospital,

Guwahati-781032,

Assam.

E-mail: taye.mrinal@gmail.com

DOI:10.14260/jemds/2016/36 theatre and postoperative wards for lower abdominal and limb surgery during the period of June, 2005 to May 2006. The study proposal was reviewed and approved by the institutional ethics committee of the hospital. The procedure was explained to the patients and written consent was obtained preoperatively.

\section{Selection of Patient}

The study included patients with ASA-I and ASA-II physical status of either sex in the age group of 22 to 61 years undergoing lower abdominal and limb surgeries. Patients with contraindications of regional anaesthesia are excluded from this study. The operative procedures required more than two hours duration are also excluded from the study.

\section{PROCEDURE}

With due aseptic precautions double interspaced CSE technique was used with L2 - 3 interspace for epidural by using 18g epidural needle with epidural catheter and the L3 4 interspace for subarachnoid block with $3 \mathrm{ml}$ of $0.5 \%$ hyperbaric bupivacaine (15mg) through a $25 \mathrm{G}$ spinal needle. Baseline pulse, blood pressure and respiratory rate and the skin temperature were recorded in supine position. Surgeries were performed under subarachnoid block. No patient was given any analgesic in the pre and intraoperative period. At the end of operation, the Elastomeric pump (Easy Pump) containing $125 \mathrm{ml}$ of bupivacaine $(0.125 \%)$ was connected with the epidural catheter and allowed to infuse continuously 
without any needs for interference. Normal saline $(0.9 \%)$ was used for dilution to make $125 \mathrm{ml}$ of $0.125 \%$ of bupivacaine.

The fill port cap was removed and the tubing clamp was closed before the solution was injected into the pump. The fill port cap was replaced once the filling of the easy pump was completed. For priming, distal end cap was loosened slightly and the clamp snapped opened. $1 \mathrm{ml}$ of fluid was allowed to fill the tubing and the line was purged to remove air bubbles by loosening and tightening the distal end cap so as to dislodge air bubbles to the distal end of the tubing. The procedure was repeated until all the air bubbled were dislodged to the distal end and finally expelled from the tubing set. Once done with, the snap clamp closed and the distal end of the cap tightened.

At the end of two hours of subarachnoid block when operation was completed the filled infusion pump was connected to the epidural catheter. The clamp snapped opened and was allowed to runs for $24 \mathrm{hrs}$. continuously. The infusion pump was disconnected when the balloon reservoir was completely collapsed and only very limited residual volume remains back in the reservoir. Epidural infusion of $0.125 \%$ bupivacaine $(5 \mathrm{ml} / \mathrm{hr}$.) was started by pre-filled Elastomeric infusion pump. Pain was assessed subjectively in this study by visual analog scale scoring system ranging from 0 to 10 .

Patients were explained about the pain score in the preoperative visit and pain-measuring scale as no pain score 0 , worst possible pain score 10 . The patients were shown a $10 \mathrm{~cm}$ line marked scale. Each patient was instructed to mark the scale at the point which he/she felt was represented of his/her level of discomfort. Then the distance from the point of 'No pain' to the marked point was measured in $\mathrm{cm}$ with a standard scale. Rescue analgesia in the form of IM inj. Ketorolac (30mg) was given when VAS was 4 or more than that.

\section{Recording of Post-Operative Parameters}

Haemodynamic parameters, quality of analgesia, degree of motor block, and adverse effect encountered were recorded at two hours interval for 24 hours at the end of two hours of subarachnoid block when operation is over. Haemodynamic parameters were recorded in the form of heart rate, diastolic and systolic blood pressure. Quality of analgesia was graded on the basis of the following visual analogue scale [VAS]-10-9, 8-7, 6-5, 4-3, 2-0 for analgesia as None, Slight, Moderate, Good, Complete analgesia respectively. Motor block was assessed using the modified Bromage scale $-0=$ No motor block, $1=$ Inability to raise extended leg. 2= Inability to flex knee, 3= Inability to move lower limb. Side effects like hypotension, bradycardia, nausea, vomiting, headache, backache, infection, etc. were looked for.

\section{STATISTICAL ANALYSIS}

Data were analysed using SPSS statistical software version 13 (SPSS Inc., Chicago, IL, USA). The total sample size was 30 patients. Data are expressed as mean \pm SD (Standard deviation) for continuous variables and number (\%) categorical variables. The demographic data were analysed using the $\mathrm{t} 2$ test. Under Null Hypothesis (H0) Students T test: Significance is determined by comparing calculated values with tabulated values of $|\mathrm{t}|$ obtained from statistical Tables. It is considered as significant when calculated ' $t$ ' is greater than tabulated $|t|$ and insignificant when calculated ' $t$ ' is smaller than tabulated $|t|$ at different levels of significance. For this study 5\% and 1\% level of significance are considered for analysis of the data.

Chi square test was applied to qualitatively analyse if the systems had any influence on the vital parameter like the pulse also suggested that the pulse rate of the patient did not have any significant influence from the systems.

\section{RESULTS AND OBSERVATIONS}

A clinical study of thirty patients of the age group of 22 to 61 years, of either sex with American Society of Anaesthesiologists physical status I and II was conducted under the Department of Anaesthesiology of Gauhati Medical College and Hospital in orthopaedic, urology, surgery and gynaecology operation theatre and postoperative wards for lower abdominal and limb surgery during the period of June 2005 to May 2006. The purpose of this study was to evaluate the application of the disposable Elastomeric balloon pumps in postoperative pain treatment by continuous infusion of bupivacaine $0.125 \%$ into the epidural space to the abovementioned patients scheduled for lower limb surgery.

The results and observations of the study are shown in the following Tables and Figures and explained thereby. It shows largest groups of patients comprising of $33.3 \%$ belonged to the 22-31 yrs. and 52-61 yrs. The minimum age was 22 yrs. and maximum was 61 yrs. The mean age in the study was $40.98 \pm 13.5$ years. Largest groups of patients comprising of $33.3 \%$ belonged to the $22-31$ yrs. and $52-61$ yrs. The minimum age was 22 yrs. and maximum was 61 yrs. The mean age in the study was $40.98 \pm 13.5$ years. [The Table shows only 6 patients in the study were with ASA status II and majorities of the patients were with ASA status I. Majority of the operations were DHS and hysterectomy. [Table 1, 2, 3, 4].

None of our patients had shown any clinically significant changes in their cardiorespiratory indices in the postoperative period. The Heart rate and MAP registered statistically insignificant $(\mathrm{P}>0.05)$ drop in the immediate postoperative period ( 0 hour) in relation to the pre-operative value and persisted to remain so for next 24 hours of infusion. The preoperative mean respiratory rate of our patients varied in the range of $17.97 \pm 2.12$ to $17.37 \pm 0.77$ from 0 hours to 20 hours after the infusion of bupivacaine was started which is insignificant [Table 5, 6, 7].

All the patients at $0 \mathrm{hr}$. were having VAS score of 0 and till 22 hours enjoyed good pain relief, i.e. VAS of 3-4. [Table 8, 9]. The number of patients receiving infusion at 20,22 and 24 hours are as 30 [100\%], 19 [63.33\%] and 11 [36.67\%] respectively indicating that the pump was emptied before completion of 24 hours as infusion is not always steady at $5 \mathrm{ml} / \mathrm{hr}$. as set by the manufacturer. [Table 10] Immediate post-operatively the entire patient had complete motor blockade and after 4 hours no patient developed complete motor loss (Bromage-3). There is no motor blockade after 16 hours (Bromage-0). [Table 11] In the present study only $3.33 \%$ patients experienced nausea or vomiting and backache. [Table 12].

\section{DISCUSSION}

In the present study we used disposable Elastomeric balloon pump to administer $0.125 \%$ of bupivacaine alone through an epidural catheter to provide post-operative analgesia to 30 patients who had undergone various lower abdominal and limb surgeries. All the patients belonged to ASA I and ASA II physical status. 
The mean age of our patients were $40.98 \pm 13.5$ years and $19(63.3 \%)$ were male while the rest $11(36.67 \%)$ were female. [Table 1, 2, 3, 4]

Pain after surgery is inevitable. Therefore, relieving pain is one of the fundamental responsibilities and a more humane and rational approach to the patient care. Further, it has been recognized that the longer the pain remains unattended; the patient becomes more sensitive to painful stimuli, prolong recovery, increase the duration of stay in the hospital and increase health care costs. ${ }^{[4]}$ Epidural local anaesthetics are capable of maintaining prolonged analgesia in the postoperative period when administered by intermittent injections or continuous infusion. ${ }^{[5,6,7]}$ Since intermittent bolus dosing has drawbacks of inconsistent analgesia, potential toxicity and compromised sterility continuous infusion of $0.125 \%$ bupivacaine is the ideal LA for epidural analgesia as it produces neural blockade of long duration, differential blockade of sensory rather than motor fibres. It blocks smaller $\mathrm{C}$ and A-delta fibres. Continuous infusion of low concentration of local anaesthetics avoids motor blockade and spare autonomic function to the urinary bladder, carries no significant toxicity and requires minimal attention from the staff in the ward. ${ }^{[8,9,10]}$

Thus Elastomeric pump which represents a technologic advance in late 80 s is relatively inexpensive disposable non mechanical pump may be proposed to provide epidural, perineural, direct wound and intra-articular local anaesthetics infusion for post-operative pain relief.[11,12 ] The pump had a capacity of $125 \mathrm{ml}$ and was designed to deliver drug @ $5 \mathrm{ml} /$ hour for 24 hours continuously. Care was also taken to look for and record any malfunctioning of the pump that could have interrupted the flow. Numerous investigators have evaluated the efficacy and safety of an Elastomeric pump in laboratory settings and also in clinical setting involving various types of surgeries and site of administration.[13,14]

None of our patients had shown any clinically significant changes in their cardiorespiratory indices in the postoperative period. The Heart rate and MAP registered statistically insignificant $(\mathrm{P}>0.05)$ drop in the immediate postoperative period ( 0 hour) in relation to the pre-operative value and persisted to remain so for next 24 hours of infusion [Table 5, 6, Figure 1,2]. The preoperative mean respiratory rate of our patients varied in the range of $17.97 \pm 2.12$ to $17.37 \pm 0.77$ from 0 hours to 20 hours after the infusion of bupivacaine was started which is insignificant [Table 7, Figure 3]. Several studies support our findings that continuous epidural infusion of $0.125 \%$ bupivacaine can safely be used for postoperative analgesia without respiratory depression.[15,16] We avoided administration of central depressant drugs to our patients and also took utmost care to perform the procedure meticulously in an attempt to prevent respiratory depression or complication.

The pain score used here was "Visual Analogue Scale" (VAS) score.[17,18] At 0 hour i.e. at the time of starting epidural infusion the VAS score was 0 in all the $30(100 \%)$ patients [Table 8, 9 Figure 4 ]. It was observed that only after 14 hours of the start of epidural infusion 1 patient had VAS 4 and needed rescue analgesia. At this point of time we found that among the rest of the 29 patients, 12 (40\%) each had VAS 0 and VAS 2 while $2(6.67 \%)$ and $3(10 \%)$ patients experienced VAS 1 and VAS 3 respectively. The Mean VAS score at 14 hour was $1.87 \pm 0.97$. Delivering the same conc. of bupivacaine Prerana
Shroff et al also found a mean VAS of $1.54 \pm 0.96$ at 14 hours in their study which is comparable to our score.

Our observation further revealed that only 5 (16.67\%) patients had no pain relief (VAS 4) and asked for rescue analgesia. On the other hand the rest of the patients were having complete or good pain relief. Various clinical studies highlight that Elastomeric balloon pumps can be relied upon for providing steady and safe pain relief. (VAS 0 -VAS 3).[19,20] Motor Block was assessed by using the modified Bromage Scale $(0=$ No blockade; $1=$ Inability to raise extended leg; $2=$ Inability to flex the knee; $3=$ inability to move lower limb. In our study all the $30(100 \%)$ patients had complete motor block (Bromage 3) at "0" hour i.e. 2 hours after SA block. All the patients recovered from complete motor block 4 hours after starting the epidural infusion. The findings at this time further showed that $6(\%)$ patients had 1st degree block (Bromage 1) while the $24(80 \%)$ among the rest were found to have clinical evidence of 2 nd degree block (Bromage 2). more than 2/3rd. of our patients $(n=22)$ had regained full movement of their legs ( 0 block) at 8 hours after the commencement of epidural infusion [Table11 Figure 5]. Findings are comparable to other studies.[21,22]

In the present study observations were made for side effects and complication like nausea, vomiting, backache, headache, infection and neurological sequelae [Table 12]. Only $1(3.33 \%)$ of our patients had the uncomfortable experience of nausea and vomiting. Some studies reported disconnection of catheters who had Elastomeric pump for ambulatory patient controlled analgesia.[23,24]

We have observed in our study that the Elastomeric balloon pump performed with remarkable degree of accuracy in all the 30 patients, providing them with satisfactory pain relief (VAS score), maintaining stable cardio respiratory parameters and subjecting none of them with any major complications. Monitoring every 2 hourly interval after starting the pump, we have observed that in all the 30 patients $(100 \%)$, the pumps were delivering continuous infusion of $0.125 \%$ bupivacaine till 20 hours (83.33\% of set duration). There are enough clinical studies that showed similar encouraging results that had used an Elastomeric pump.[25,26] We should keep the flow restrictor of the pump in close contact with the skin of the patients to ensure flow accuracy (Minimal temperature variation). This is reason of variable flow rate in elastomeric pump sometimes.[27,28]

\section{CONCLUSION}

Elastomeric balloon pumps a reliable device to deliver LA agents steadily and safely with $0.125 \%$ bupivacaine as continuous epidural infusion for providing satisfactory postoperative analgesia in lower abdominal and limb surgeries. The changes in pulse rate, mean arterial pressure and respiratory rates were insignificant. Side effects such as nausea, vomiting, backache, headache or any kinds of neurological sequelae were negligible.

\section{REFERENCES}

1. Sara Korula, Grace Maria George, Shaloo Ipe, et al. Epidural anesthesia and post-operative analgesia for bilateral inguinal mesh hernioplasty: Comparison of equipotent doses of ropivacaine and bupivacaine. Saudi J Anaesth. 2011;5:277-281. 
2. Ertaş IE, Sehirali S, Ozsezgin Ocek S, Sancı M, Arbak G, Yıldırım Y. The effectiveness of subcutaneously implanted epidural ports for relief of severe pain in patients with advanced-stage gynaecological cancer: a prospective study. Agri. 2014;26:8-14.

3. Wheatley RG, Schug SA, Watson D. Safety and efficacy of postoperative epidural analgesia. Br J Anaesth 2001;87:47.

4. GH Wheatley, III, David H Rosenbaum, Michelle C Paul, Improved pain management outcomes with continuous infusion of a local anesthetic after thoracotomy. J Thorac Cardiovasc Surg 2005;130:464-68.

5. Shaw, Brian A Watson, Timothy C. The safety of continuous epidural infusion for postoperative analgesia in Pediatric Spine Surgery. Journal of Pediatric Orthopaedics. 1996;16:374-77.

6. Dauri M, Polzoni M, Fabbi E, Sidiropoulou T, Servetti S, Coniglione $\mathrm{F}$, et al. Comparison of epidural, continuous femoral block and intra-articular analgesia after anterior cruciate ligament reconstruction. Acta Anaesthesiol Scand. 2003;47:20-25.

7. Hernández-Palazón JA, Tortosa Serrano, Martínez-Pérez $M$, et al. The efficacy of continuous bupivacaine infiltration following anterior cruciate ligament reconstruction. Rev Esp Anestesiol Reanim. 2001;48:59-64.

8. Olivier JF, Le N, Choinière JL, Prieto I, Basile F, Hemmerling T. Comparison of three different epidural solutions in offpump cardiac surgery: pilot study. BJ Anaesth. 2005;95:685-691.

9. White JL, Stevens RA, Kao TC. Differential sensory block: spinal vs epidural with lidocaine. Can J Anaesth 1998;45:1049-53.

10. Zhan 28, Yamaguchi S, Kitamura J, et al. Evaluation of motor block of the lower legs in continuous lumbar epidural infusion of ropivacaine. Masui. 2012;61:583-7.

11. Ik Soo Chung, Hyun Sung Cho, Jie Ae Kim. The flow rate of the elastomeric balloon infusor is influenced by the internal pressure of the infusor- J Korean Med Sci 2001;16:702.

12. Ilfeld BM, Morey TE, Enneking FK. The delivery rate accuracy of portable infusion pumps used for continuous regional analgesia. Anesth Analg. 2004;95:133-6.

13. Stephen M Klein, MD; Roy A Greengrass, MD, FRCP; David $\mathrm{H}$ Gleason, CRNA; et al. Major ambulatory surgery with continuous regional anesthesia and a disposable infusion pump, Anesthesiology, 1999;91:563-5.

14. Izquierdo-Mediavilla A, Garcia-Escobar M, GonzalezMachado JL. Tramadol in elastomeric continuous perfusion for analgesia after gynecologic surgery. Rev Esp Anestesiol Reanim. 1997;44:330-2.

15. LeBlanc KA, Bellanger D, Rhynes VK, et al. Evaluation of continuous infusion of $0.5 \%$ bupivacaine by elastomeric pump for postoperative pain management after open inguinal hernia repair. J Am Coll Surg. 2005;200:198-202.

16. Shroff P, Ahuja P, Chandra S, et al. Comparative study of epidural tramadol $\mathrm{v} / \mathrm{s}$ bupivacaine for postoperative analgesia using disposable non-mechanical elastomeric balloon pump. bhj. 2004;46:04.
17. French T, Hewlett S, Kirwan J, et al. Different wording of the Patient Global Visual Analogue Scale (PG-VAS) affects rheumatoid arthritis patients' scoring and the overall Disease Activity Score (DAS28): a cross-sectional study. Musculoskeletal Care. 2013;11:229-37.

18. Sugantha Ganapathy, Annunziato Amendola, Robert Lichfield, et al. Elastomeric pumps for ambulatory patient controlled regional analgesia Canadian Journal of Anesthesia. 2000;47:897-902.

19. Coley SC, Shaw PK and Leff RD. The performance of three portable infusion-pump devices set to deliver $2 \mathrm{ml} / \mathrm{hr}$. Am J Health Syst Pharm. 1997;54:1277-80.

20. Losken A, Parris JJ, Douglas TD, et al. Use of the infusion pain pump following transverse rectus abdominis muscle flap breast reconstruction. Ann Plast Surg. 2005;54:47982.

21. Graham AC, McClure JH. Quantitative assessment of motor block in labouring women receiving epidural analgesia. Anaesthesia. 2001;56:470-6.

22. John AC, Murdoch, Ursula K, et al. The efficacy and safety of three concentrations of levobupivacaine administered as a continuous epidural infusion in patients undergoing orthopedic surgery. Anesth Analg 2002;94:438-444.

23. Matsumoto S, Mitsuhata H, Shigeomi S, Matsumoto J, Yabe M, Terada M. Evaluation of the safety of a new portable pump for continuous epidural infusion of local anesthetics. Masui 1990;39:1245-51.

24. Shaw, Brian A Watson, Timothy C. The safety of continuous epidural infusion for postoperative analgesia in pediatric spine surgery. Journal of Pediatric Orthopaedics. 1996;16:374-77.

25. Gehdoo RP, Jain PN, Anup Arora, et al. Continuous infusion of epidural morphine and bupivacaine for postoperative pain relief -a prospective study. Indian J Anaesth. 2003;47:454-455.

26. Ertaş IE, Sehirali S, Ozsezgin Ocek S, Sancı M, Arbak G, Yıldırım Y. The effectiveness of subcutaneously implanted epidural ports for relief of severe pain in patients with advanced-stage gynaecological cancer: a prospective study. Agri. 2014;26:8-14.

27. Stull JC, Schneider PJ, Erenberg A, et al. Decreased flow accuracy from volumetric infusion pumps. Crit Care Med. 1989;17:926-8.

28. Valente $\mathrm{M}$ and Aldrete JA. Comparison of accuracy and cost of disposable, non-mechanical pumps used for epidural infusions. Reg Anesth. 1997;22:260.

\begin{tabular}{|c|c|c|c|}
\hline $\begin{array}{c}\text { Age Group } \\
\text { in Years }\end{array}$ & $\begin{array}{c}\text { No. of } \\
\text { Cases }\end{array}$ & $\begin{array}{c}\text { Percentage } \\
\text { \% }\end{array}$ & $\begin{array}{c}\text { Mean Age } \\
\text { in Years }\end{array}$ \\
\hline $22-31$ & 10 & 33.3 & \\
\cline { 1 - 3 } $42-41$ & 3 & 10 & \multirow{2}{*}{$40.98 \pm 13.5$} \\
\hline $42-51$ & 7 & 23.3 & \\
\hline $52-61$ & 10 & 33.3 & \\
\cline { 1 - 2 } Table 1: Age variables with Mean \& \\
standard Deviation \\
\hline
\end{tabular}

\begin{tabular}{|c|c|c|}
\hline Sex & No. of Patients & Percentage (\%) \\
\hline Male & 19 & 63.33 \\
\hline Female & 11 & 36.67 \\
\hline \multicolumn{3}{|c|}{ Table 2: Table shows the } \\
percentage distribution of sex
\end{tabular}




\begin{tabular}{|c|c|c|}
\hline ASA status & $\begin{array}{c}\text { No. of } \\
\text { patients }\end{array}$ & Percentage (\%) \\
\hline ASA-I & 24 & $80 \%$ \\
\hline ASA-II & 6 & $20 \%$ \\
\hline \multicolumn{2}{|c|}{ Table 3: ASA status of the patients } \\
\hline
\end{tabular}

\begin{tabular}{|c|c|c|c|}
\hline $\begin{array}{c}\text { Sl. } \\
\text { No. }\end{array}$ & $\begin{array}{c}\text { Type of } \\
\text { Operation }\end{array}$ & $\begin{array}{c}\text { No. of } \\
\text { Patient }\end{array}$ & (\%) \\
\hline I & DHS & 15 & \\
\hline II & Pyelolithotomy & 3 & \\
\hline III & Obstructed inguinal hernia & 5 & \\
\hline IV & Hysterectomy & 8 & \\
\hline \multicolumn{3}{|c|}{ Table 4: Different types of } \\
operations taken for the study \\
\hline
\end{tabular}

\begin{tabular}{|c|c|c|c|c|}
\hline $\begin{array}{c}\text { Pre } \\
\text { operative } \\
\text { mean } \\
\text { MAP } \\
\text { mmHg } \\
\text { (Mean } \\
\pm \text { SD) }\end{array}$ & $\begin{array}{c}\text { Post- } \\
\text { operative } \\
\text { Interval }\end{array}$ & $\begin{array}{c}\text { Postoperative } \\
\text { Mean MAP } \\
\text { mmHg } \\
\text { (Mean } \pm \text { SD) }\end{array}$ & $\begin{array}{l}\text { Mean } \\
\text { change }\end{array}$ & $\begin{array}{c}\% \\
\text { Change } \\
\text { of } \\
\text { mean } \\
\text { MAP } \\
\text { (Mean } \\
\pm \text { SD) }\end{array}$ \\
\hline \multirow{13}{*}{$96.17 \pm 8.17$} & 0 hour & $88.83 \pm 5.15$ & -7.34 & -7.6 \\
\hline & 2 hours & $87.50 \pm 3.75$ & -8.67 & -9.01 \\
\hline & 4 hours & $86.13 \pm 3.00$ & -10.04 & -10.43 \\
\hline & 6 hours & $85.00 \pm 3.22$ & -11.17 & -11.60 \\
\hline & 8 hours & $87.56 \pm 3.59$ & -8.61 & -8.90 \\
\hline & 10 hours & $90.36 \pm 2.82$ & -5.81 & -6.04 \\
\hline & 12 hours & $90.83 \pm 2.46$ & -5.34 & -5.60 \\
\hline & 14 hours & $91.06 \pm 2.31$ & -5.11 & -5.30 \\
\hline & 16 hours & $90.90 \pm 2.98$ & -5.27 & -5.47 \\
\hline & 18 hours & $92.13 \pm 3.19$ & -4.04 & -4.20 \\
\hline & 20 hours & $91.93 \pm 4.17$ & -4.24 & -4.40 \\
\hline & 22 hours & $92.84 \pm 4.99$ & -3.33 & -3.46 \\
\hline & 24 hours & $96.72 \pm 4.52$ & 0.55 & 0.57 \\
\hline
\end{tabular}

\begin{tabular}{|c|c|c|c|c|}
\hline $\begin{array}{c}\text { Pre } \\
\text { operative } \\
\text { Mean } \\
\begin{array}{c}\text { Pulse/min } \\
\text { (Mean } \pm \text { SD) }\end{array}\end{array}$ & $\begin{array}{c}\text { Post } \\
\text { operative } \\
\text { Interval }\end{array}$ & $\begin{array}{c}\text { Mean } \\
\text { Pulse } \\
\mathbf{\pm S D} / \mathbf{m i n} \\
\text { Post } \\
\text { operative }\end{array}$ & $\begin{array}{c}\text { Mean } \\
\text { Change }\end{array}$ & $\begin{array}{c}\text { \% } \\
\text { Change } \\
\text { of } \\
\text { Mean } \\
\text { pulse }\end{array}$ \\
\hline \multirow{7}{*}{$82.69 \pm 11.4$} & 0 hour & $79.03 \pm 8.22$ & -3.66 & -4.42 \\
\cline { 2 - 5 } & 2 hours & $77.07 \pm 7.38$ & -5.62 & -6.80 \\
\cline { 2 - 5 } & 4 hours & $76.2 \pm 4.96$ & -6.49 & -7.84 \\
\cline { 2 - 5 } & 6 hours & $76.97 \pm 4.89$ & -5.72 & -6.91 \\
\cline { 2 - 5 } & 8 hours & $79.03 \pm 7.76$ & -3.66 & -4.42 \\
\cline { 2 - 5 } & 10 hours & $79.56 \pm 6.35$ & -3.13 & -3.78 \\
\cline { 2 - 5 } & 12 hours & $80.76 \pm 5.6$ & -1.93 & -2.33 \\
\cline { 2 - 5 } & 14 hours & $80.9 \pm 5.63$ & -1.79 & -2.16 \\
\cline { 2 - 5 } & 16 hours & $82.3 \pm 5.56$ & -0.39 & -0.47 \\
\cline { 2 - 5 } & 18 hours & $81.9 \pm 5.21$ & -0.79 & -0.96 \\
\cline { 2 - 5 } & 20 hours & $81.86 \pm 5.97$ & -0.83 & -1.00 \\
\cline { 2 - 5 } & 22 hours & $80.32 \pm 4.78$ & -2.37 & -2.87 \\
\cline { 2 - 5 } & 24 hours & $82.62 \pm 8.95$ & -0.07 & -0.84 \\
\hline
\end{tabular}

Mean Pulse rate and mean change and percentage change of the mean pulse rate at different postoperative interval in relation to preoperative value.

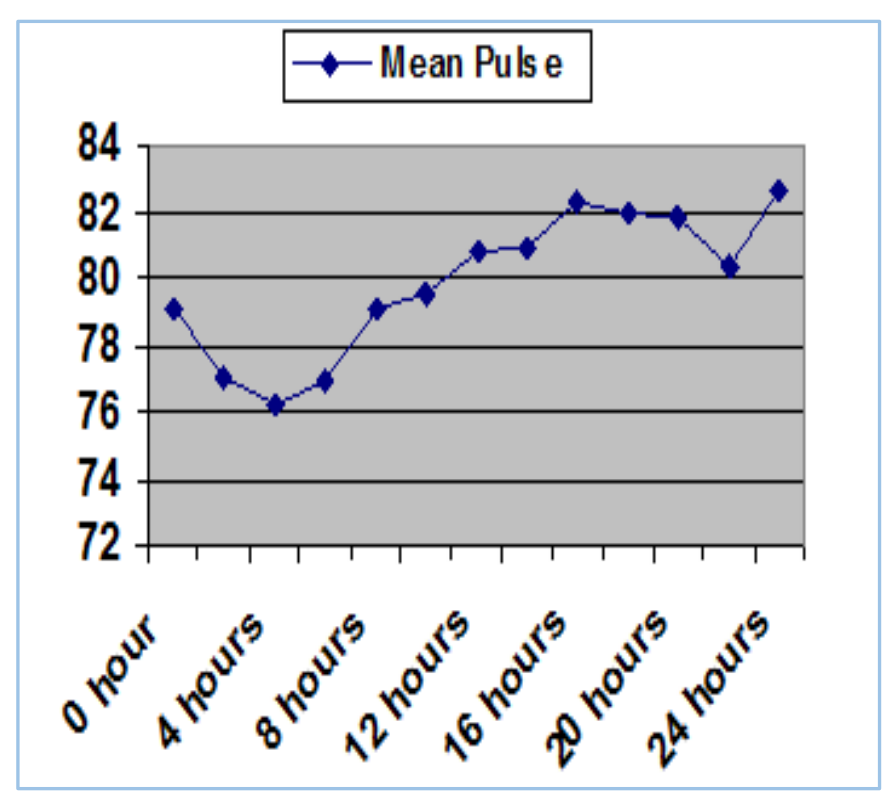

Fig. 1: Graph showing the Mean Pulse at Different Time Interval

\begin{tabular}{|c|c|c|c|c|}
\hline $\begin{array}{c}\text { Pre } \\
\text { operative } \\
\text { Mean } \\
\text { Resp. rate/ } \\
\text { Min } \\
\text { (Mean } \pm \text { sD) }\end{array}$ & $\begin{array}{c}\text { Post } \\
\text { operative } \\
\text { interval }\end{array}$ & $\begin{array}{c}\text { Post } \\
\text { operative } \\
\text { Mean } \\
\text { Resp. rate } \\
\text { (Mean } \pm \text { SD) }\end{array}$ & $\begin{array}{l}\text { Mean } \\
\text { Change }\end{array}$ & $\begin{array}{l}\% \text { Change } \\
\text { of Mean } \\
\text { Resp. rate } \\
\text { (Mean } \pm \text { SD }\end{array}$ \\
\hline \multirow{13}{*}{$18.3 \pm 3.28$} & 0 hour & $17.97 \pm 2.12$ & -0.33 & -1.80 \\
\hline & 2 hours & $17.63 \pm 0.82$ & -0.67 & -3.66 \\
\hline & 4 hours & $17.13 \pm 1.23$ & -0.17 & -0.92 \\
\hline & 6 hours & $16.93 \pm 1.09$ & -1.37 & -7.48 \\
\hline & 8 hours & $17.97 \pm 1.00$ & -0.33 & -1.80 \\
\hline & 10 hours & $18.1 \pm 0.94$ & -0.20 & -1.09 \\
\hline & 12 hours & $21.4 \pm 0.89$ & +3.10 & +16.93 \\
\hline & 14 hours & $21.4 \pm 0.86$ & +3.10 & +16.93 \\
\hline & 16 hours & $17.6 \pm 0.82$ & -0.70 & -3.82 \\
\hline & 18 hours & $18.07 \pm 0.79$ & -0.23 & -1.25 \\
\hline & 20 hours & $17.37 \pm 0.77$ & -0.93 & -5.08 \\
\hline & 22 hours & $18.00 \pm 1.45$ & -0.30 & -1.63 \\
\hline & 24 hours & $18.90 \pm 1.57$ & 0.60 & 3.37 \\
\hline \multicolumn{5}{|c|}{ Table 7} \\
\hline
\end{tabular}

Mean Respiratory rate along with mean change and percentage change in different postoperative interval in relation to preoperative value. 


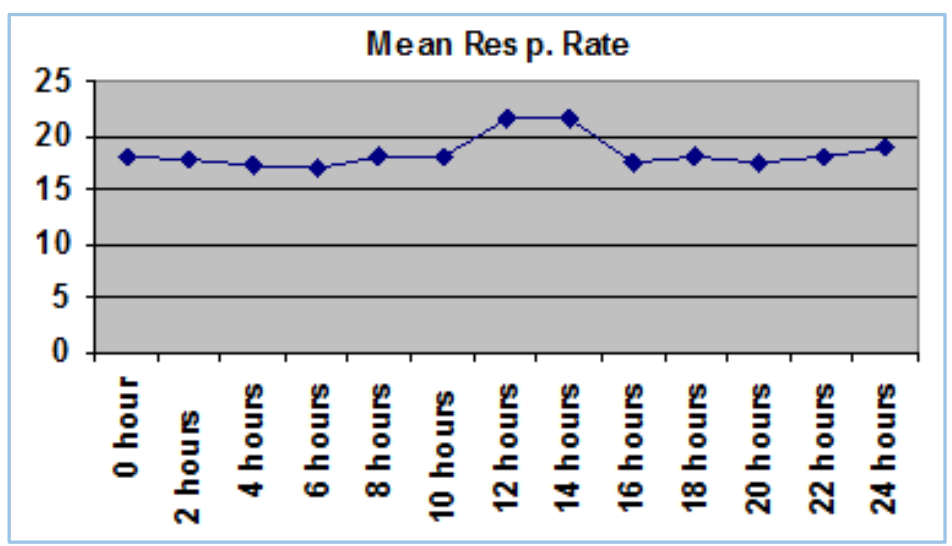

Fig. 3: Graph showing Postoperative Mean Respiratory Rate

\begin{tabular}{|l|c|c|c|c|c|c|c|c|c|c|c|c|c|}
\hline & $\begin{array}{c}\mathbf{0} \\
\text { hrs. }\end{array}$ & $\mathbf{2}$ hrs. & $\mathbf{4}$ hrs. & $\mathbf{6}$ hrs. & $\mathbf{8}$ hrs. & $\begin{array}{c}\mathbf{1 0} \\
\text { hrs. }\end{array}$ & $\begin{array}{c}12 \\
\text { Hrs. }\end{array}$ & 14hrs. & 16hrs. & 18hrs. & $\begin{array}{c}\mathbf{2 0} \\
\text { hrs. }\end{array}$ & $\begin{array}{c}\mathbf{2 2} \\
\text { hrs. }\end{array}$ & $\mathbf{2 4}$ hrs. \\
\hline VAS 0 & 30 & 25 & 27 & 24 & 20 & 14 & 12 & 12 & 5 & 4 & 7 & 2 & - \\
\hline VAS 1 & - & 2 & 1 & 15 & 8 & 7 & 3 & 2 & 11 & 3 & 6 & 1 & - \\
\hline VAS 2 & - & 3 & 2 & - & 2 & 9 & 11 & 12 & 13 & 15 & 5 & 6 & - \\
\hline VAS 3 & - & - & - & - & - & - & 4 & 3 & 1 & 8 & 7 & 3 & 3 \\
\hline VAS 4 & - & - & - & - & - & - & - & 1 & - & & 5 & 7 & 8 \\
\hline \multicolumn{19}{|c|}{ Table 8 } \\
\hline
\end{tabular}

Different grades of pain relief with relevant pain score (VAS) during postoperative period

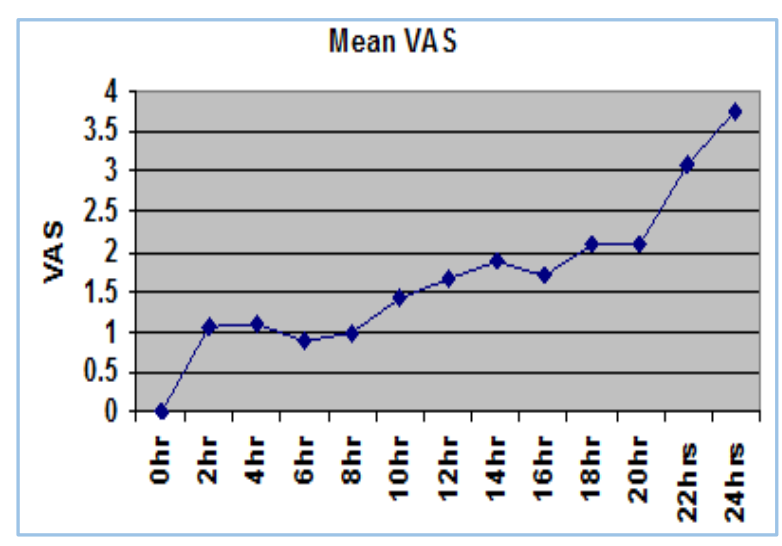

Fig. 4: Diagram showing

Visual Analogue Scale (VAS) Score

\begin{tabular}{|c|c|}
\hline Post-operative Interval & VAS Mean \pm SD \\
\hline $0 \mathrm{Hr}$ & 0 \\
\hline $2 \mathrm{Hrs}$ & $1.07 \pm 0.70$ \\
\hline $4 \mathrm{Hrs}$ & $1.1 \pm 0.77$ \\
\hline $6 \mathrm{Hrs}$ & $0.9 \pm 0.59$ \\
\hline $8 \mathrm{Hrs}$ & $1 \pm 0.86$ \\
\hline $10 \mathrm{Hrs}$ & $1.4 \pm 0.93$ \\
\hline $12 \mathrm{Hrs}$ & $1.7 \pm 0.98$ \\
\hline $14 \mathrm{Hrs}$ & $1.8 \pm 0.93$ \\
\hline $16 \mathrm{Hrs}$ & $1.7 \pm 0.82$ \\
\hline $18 \mathrm{Hrs}$ & $2.1 \pm 0.93$ \\
\hline $20 \mathrm{Hrs}$ & $2.1 \pm 1.34$ \\
\hline $22 \mathrm{hrs}$ & $3.09 \pm 0.99$ \\
\hline $24 \mathrm{hrs}$ & $3.75 \pm 0.46$ \\
\hline \multicolumn{2}{|c|}{ Table 9: Showing Mean Vas and } \\
its Mean \& Standard deviation \\
\hline
\end{tabular}

\begin{tabular}{|c|c|c|}
\hline $\begin{array}{c}\text { Duration of } \\
\text { Infusion } \\
\text { by Elastomeric } \\
\text { pump }\end{array}$ & $\begin{array}{c}\text { No. of Patient } \\
\text { Receiving } \\
\text { Infusion }\end{array}$ & $\begin{array}{c}\text { Percentage of } \\
\text { No. of Patient } \\
\text { Receiving } \\
\text { Infusion (\%) }\end{array}$ \\
\hline $0-20 \mathrm{Hrs}$ & 30 & 100 \\
\hline $0-22 \mathrm{Hrs}$ & 19 & 63.33 \\
\hline $0-24 \mathrm{Hrs}$ & 11 & $36.67 \%$ \\
\hline \multicolumn{3}{|c|}{ Table 10 } \\
\hline \multicolumn{2}{|c}{}
\end{tabular}

The above Table showing number of patient receiving infusion at 20, 22 and 24 hours as 30 [100\%], 19 [63.33\% ] and $11[36.67 \%]$ respectively indicating that the infusion is not always steady at $5 \mathrm{ml} / \mathrm{hr}$. as set by the manufacturer.

\begin{tabular}{|c|c|c|c|c|}
\hline \multirow{2}{*}{$\begin{array}{c}\text { Post- } \\
\text { operative } \\
\text { interval }\end{array}$} & \multicolumn{4}{|c|}{$\begin{array}{c}\text { Degree of Motor Blockade } \\
\text { (No. of Cases) }\end{array}$} \\
\cline { 2 - 5 } & $\begin{array}{c}\text { 0-No } \\
\text { blockade }\end{array}$ & $\begin{array}{c}\text { 1st- } \\
\text { degree }\end{array}$ & $\begin{array}{c}\text { 2nd- } \\
\text { degree }\end{array}$ & $\begin{array}{c}\text { 3rd- } \\
\text { degree }\end{array}$ \\
\hline 0 hour & & & & 30 \\
\hline 2 hours & & & 11 & 19 \\
\hline 4 hours & & 6 & 24 & \\
\hline 6 hours & 4 & 26 & & \\
\hline 8 hours & 22 & 8 & & \\
\hline 10 hours & 23 & 7 & & \\
\hline 12 hours & 24 & 6 & & \\
\hline 14 hours & 25 & 5 & & \\
\hline 16 hours & 28 & 2 & & \\
\hline 18 hours & 30 & & & \\
\hline 20 hours & 30 & & & \\
\hline 22 hours & 30 & & & \\
\hline 24 hours & 30 & & & \\
\hline
\end{tabular}

Table 11: Showing degree of motor blockade using a modified Bromage score in the postoperative period 


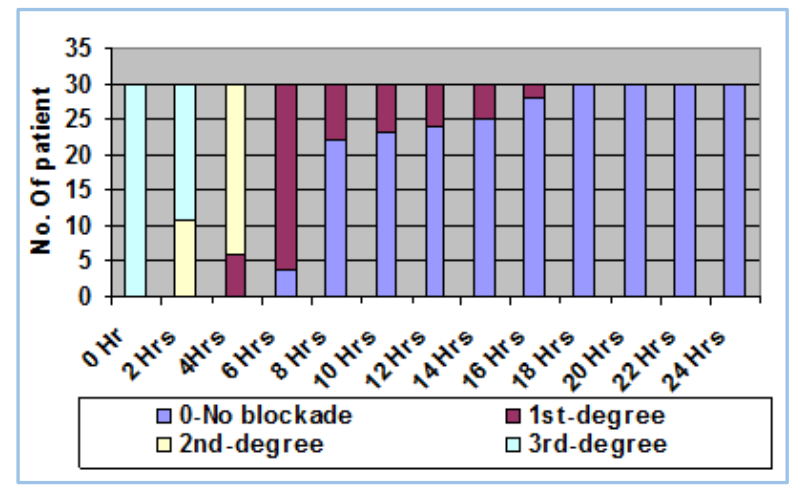

\begin{tabular}{|c|c|c|}
\hline Adverse Effect & No. of Patient & Percentage (\%) \\
\hline Nausea/Vomiting & 1 & 3.33 \\
\hline Backache & 1 & 3.33 \\
\hline Headache & 0 & 0 \\
\hline Resp. Depression & 0 & 0 \\
\hline Infection & 0 & 0 \\
\hline Neurological & 0 & 0 \\
\hline \multicolumn{2}{|c|}{ Table 12: Showing adverse effects } \\
found in the present study \\
\hline
\end{tabular}

Fig. 5: Bar diagram showing motor blockade by using modified Bromage score 